Article

\title{
Agricultural Soil Alkalinity and Salinity Modeling in the Cropping Season in a Spectral Endmember Space of TM in Temperate Drylands, Minqin, China
}

\author{
Danfeng Sun * and Wanbei Jiang
}

Land Resources and Management Department, College of Natural Resources and Environmental Science, China Agricultural University, Beijing 100193, China; jiangwanbei@cau.edu.cn

* Correspondence: sundf@cau.edu.cn; Tel.: +86-10-6373-3869

Academic Editors: José A.M. Demattê, James Campbell, Clement Atzberger and Prasad S. Thenkabail Received: 4 July 2016; Accepted: 25 August 2016; Published: 31 August 2016

\begin{abstract}
This paper presents the potential of the four-image spectral endmember (EM) space comprising sand (SL), green vegetation (GV), saline land (SA), and dark materials (DA), unmixed from Landsat TM/ETM+ to map dryland agricultural soil alkalinity and salinity (i.e., soil alkalinity $(\mathrm{pH})$ and soil electrical conductivity $(\mathrm{EC}))$ in the shallow root zone $(0-20 \mathrm{~cm})$ using partial least squares regression (PLSR) and an artificial neural network (ANN). The results reveal that SA, SL, and GV fractions at the subpixel level, and land surface temperature (LST) are necessary independent variables for soil EC modeling in Minqin Oasis, a temperate-arid system in China. The $\mathrm{R}^{2}$ (coefficient of determination) of the optimized parameters with the ANN model was 0.79, the root mean squared error (RMSE) was 0.13 , and the ratio of prediction to deviation (RPD) was 1.95 when evaluated against all sampled data. In addition to the aforementioned four variables, the DA fraction and the recent historical SA fraction (SAH) in the spring dry season in 2008 were also helpful for soil $\mathrm{pH}$ modeling. The model performance is $\mathrm{R}^{2}=0.76$, RMSE $=0.24$, and $\mathrm{RPD}=1.96$ for all sampled data. In summary, the stable EMs and LST space of TM imagery with an ANN approach can generate near-real-time regional soil alkalinity and salinity estimations in the cropping period. This is the case even in the critical agronomic range (EC of $0-20 \mathrm{dS} \cdot \mathrm{m}^{-1}$ and $\mathrm{pH}$ of 7-9) at which researchers and policy-makers require near-real-time crop management information.
\end{abstract}

Keywords: dryland soil alkalinity and salinity; spectral end-member; land surface temperature; crop season; artificial neural network; TM/ETM+

\section{Introduction}

Soil alkalinity and salinity is one of the most serious causes of desertification [1,2], and it is a major environmental hazard in dryland systems [3-5]. Under the increasing population pressure, soil sodification and salinization hazards will increase with expanded irrigation system use [3]. Usually, soil alkalinity and salinity in the shallow root zone $(0-20 \mathrm{~cm})$ are major threats for crop emergence and seedling growth in dryland oases [6]. Furthermore, the effects of alkalinity and salinity on plant productivity are not linear, and they interact with other stress factors (such as soil erosion, drought, and nutrient loss) in the root zone [7,8]. Thus, a rapidly responding and cost-effective technique is required for the assessment of regional soil alkalinity and salinity dynamics and status in the root zone for adaptive crop management in a dryland oasis.

To date, a large variety of remote sensing techniques have been applied for identifying and monitoring salt-affected areas, including multispectral, microwave, hyperspectral, and high-spatial multispectral images [1]. There is renewed interest in the use of broadband multispectral imagery for regional soil salt content prediction (e.g., [4,5,9-16]). Generally, these studies include (1) the 
bands' selection and investigation of spectral indices, including salinity indices and vegetation indices (e.g., [12,13]); (2) the optimized combination of bands and spectral indices for modeling, such as $[4,5,14]$; and (3) the long-term soil salinity dynamic analysis, such as in References $[15,16]$. Current studies focus mainly on surface saline spectral features in areas with little or no vegetation in the dry season. The results indicate that the various spectral reflectance combinations (indices) and methods performed inconsistently [11]. Some multispectral studies have also combined soil environmental covariates in agricultural soil salinity assessment models (e.g., $[10,17])$. However, the contribution of individual covariates can be inconsistent [18], partly due to the mismatch of spatio-temporal resolution and the quality of ancillary data [10]. In addition, the thermal band of TM imagery-as an important indicator for water - energy balance is rarely applied to the quantitative modeling of soil alkalinity and salinity. Therefore, it is necessary to fully explore the potential of current broadband remote sensing (e.g., the Landsat series) in modeling cropland alkalinity and salinity dynamics and status during the cropping period.

The generic SVD (i.e., Soils and substrates, Vegetation, and Dark surface endmembers) model has been developed in the spectral mixing spaces of TM/ETM+ $[19,20]$, providing the relative proportion of SVD at the subpixel level. The SVD, however, is needed to calibrate in the different geographic/ecological areas for local basic cover types [21]. The specific SVD four-endmember model (i.e., SL, sand land; SA, saline land; GV, green vegetation; and DA, dark materials) in the multidate TM imagery was validated and applied to intra-annual cover classification and inter-annual change detection in the temperate dryland system of Minqin, China [21,22]. In the stable SVD space, land cover can be identified without the known training areas; moreover, EMs (spectral endmembers) are easily validated and converted into the typical biophysical attributes [23-25]. The potential of SVD space unmixing from TM imagery has not yet been evaluated for agricultural soil alkalinity/salinity quantitative modeling in cropping periods.

Partial least squares regression (PLSR) and artificial neural networks (ANN) are both popular approaches for the quantification of such relations. Soil salinity and soil reflectance can be approximated by a linear function in the absence of the disturbance of other environmental variables, and thus, there is a large similarity between the two approaches, and PLSR has the advantage of relative simplicity compared to ANN [26]. The advantage of ANN is its nonlinear quantification of complex processes at the regional scale, and it was successfully used to estimate the spatial distribution of soil salinity based on complex environmental parameters (terrain indices, distance to drains, and long-term groundwater observation data) with ETM+ data (vegetation index, the raw bands 3 and 5) [17]. In addition, the stable and easy-to-interpret SVD can possibly reduce the shortcomings of ANN as a "black box" approach [27], and its requirement of large training samples [28].

Therefore, in this paper, we attempted SVD with broadband imagery (e.g., TM/ETM+) as a generic procedure to empirically retrieve regional soil alkalinity and salinity data in the shallow root zone $(0-20 \mathrm{~cm})$ in the cropping season. The specific objectives were (1) to investigate the ability of SVD and LST (land surface temperature) to describe the process between crop growth and solute transport in the shallow root zone during the crop-growing period; and (2) to assess the potential of PLSR and ANN in modeling agricultural soil salinity and alkalinity in the EMs and LST space.

\section{Materials and Methods}

\subsection{Study Area and in Situ Measurements}

The temperate-arid dryland system of Minqin County is a 2000-year-old desert oasis located in the northeastern region of the Hexi Corridor, on the lower reaches of the Shiyang River in Gansu Province, Northwest China $\left(38^{\circ} 03^{\prime} \mathrm{N}\right.$ to $39^{\circ} 28^{\prime} \mathrm{N}, 101^{\circ} 49^{\prime} \mathrm{E}$ to $104^{\circ} 12^{\prime} \mathrm{E}$, Figure 1$)$. As an inland dryland system at the bottom of the inland Shiyang River, playas have developed (i.e., dry salt lake indicated in Figure 1), at local depressions or in foot areas of local residual hills (i.e., salinized sandland in Figure 1). 
Excessive and unreasonable irrigation with low-quality groundwater is the major cause of secondary sodification and salinization in the oasis $[29,30]$.

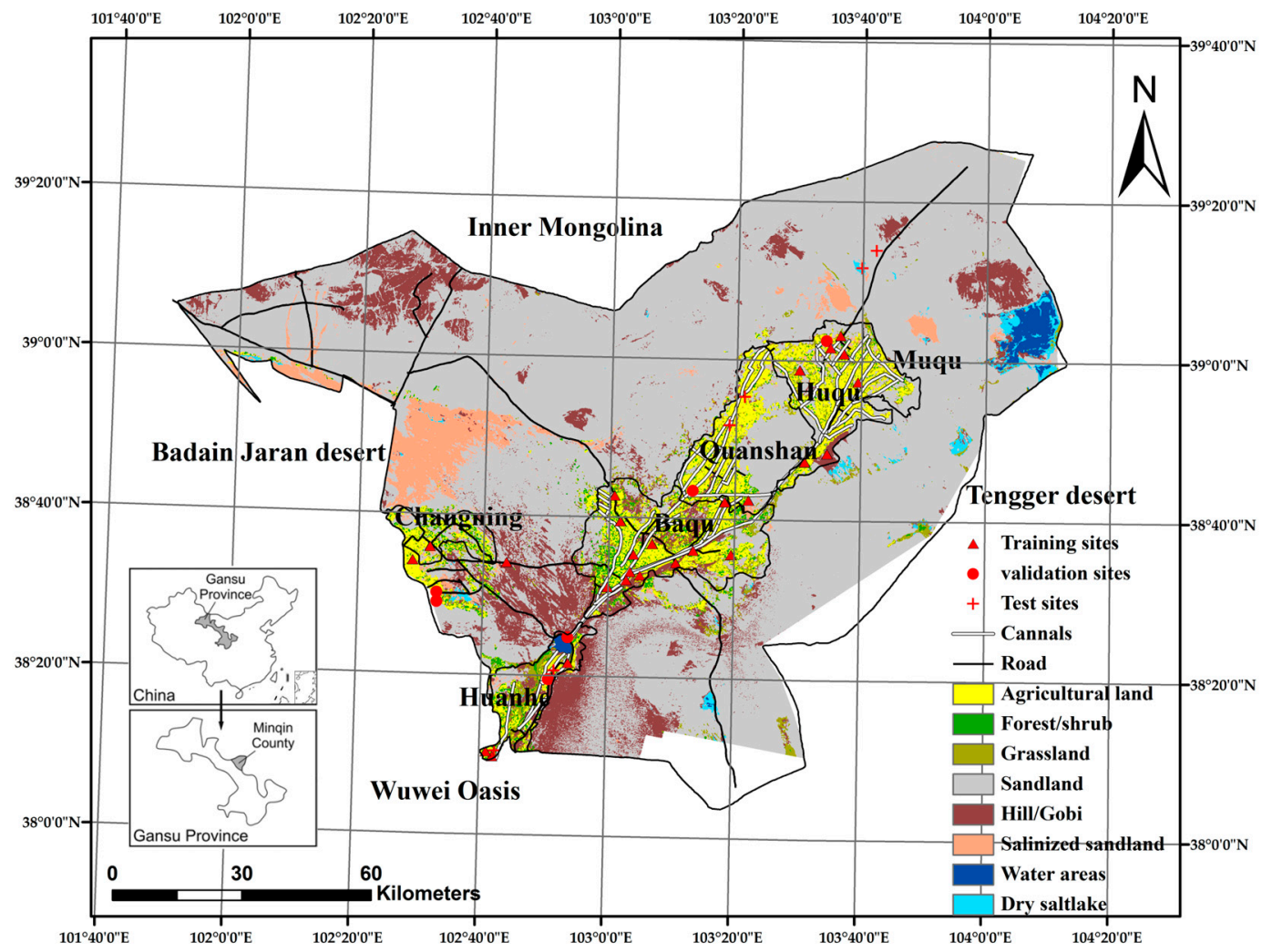

Figure 1. The 2008 land use and 2010 field sites in the study area.

Based on the 2008 dryland use map [21], we sampled 38 field sites during 7-15 September 2010, in agricultural areas (Figure 1). Each site was a $30 \times 30 \mathrm{~m}^{2}$ plot around the center point, and was further divided into four subplots to sample soil in the shallow root zone $(0-20 \mathrm{~cm})$. EC (soil electrical conductivity) and $\mathrm{pH}$ (soil reaction) were used to indicate the regional salinity and alkalinity, respectively. The EC was determined in a 1:5 soil-water aqueous extract with a model DDS-307 conductivity meter (REX Instrument Factory, Shanghai, China). Soil $\mathrm{pH}$ was determined using a PHS-3C pH meter (REX Instrument Factory, Shanghai, China) by mixing $10 \mathrm{~g}$ soil with $25 \mathrm{~mL} 0.01 \mathrm{M}$ $\mathrm{Cacl}_{2}$ solution following the ISSCAS standard methods [31].

\subsection{Remote Sensing Data and Preprocessing}

An outline of the data processing flow is shown in Figure 2. Two Landsat 5 TM scenes (path 131, row 33, and path 132, row 33) cover the study area, and the 16 day temporal resolution means that it is difficult to identify sufficient cloud-free TM images that correspond to phenological events. Furthermore, remote sensing data were not available for the dates on which field data were obtained. One image (131/33) was collected on 15 July 2010, and the other (132/33) on 23 August 2010 (about two months and one month in advance of the fieldwork dates, respectively), and they belong to the same phenology. The image (131/33) includes a few clouds in the northeastern areas, but these parts were not used for modeling.

The geometrically-rectified 2008 images [21] were used as references to co-register and correct the TM images in 2010, and the average half-pixel image-to-image co-registration accuracy was achieved. These images were atmospherically corrected using the FLAASH (Fast Line-of-sight Atmospheric Analysis of Hypercubes) module of the ENVI 4.8 software for radiance to reflectance conversion, according to the corresponding image information. 
A fully constrained linear spectral mixing analysis (LSMA) with the 2008 EM spectra set from Sun and Liu [21] was performed based on 2010 images to generate the corresponding EM fractions(Figure 3a-d). A full description of the dimensional mixing space and EMs selection in the study area was given in Sun and Liu [21]. The mean overall root mean squared error (RMSE) and its standard deviation for the two scenes were 0.015 and 0.003 , less than 0.02 , respectively, suggesting a generally good fit according to the study of $\mathrm{Wu}$ and Murray [32].

LST was derived from thermal band of Landsat TM data. The digital grey values of the thermal band were first converted to physical measurements of at-sensor radiance following the Landsat User's Handbook [33]. The radiance data were then transformed into radiant surface temperatures using the thermal calibration constants supplied by Mtakham and Barker [34], as follows:

$$
T_{S}=\frac{K_{2}}{\operatorname{Ln}\left(K_{1} / L_{\lambda}+1\right)}-273.15
$$

where $T s$ is the radiant surface temperature $\left({ }^{\circ} \mathrm{C}\right)$, and $K_{1}$ and $K_{2}\left(\mathrm{~m} \mathrm{~W} \cdot \mathrm{cm}^{-2} \cdot \mathrm{sr}^{-1} \cdot \mu \mathrm{m}^{-1}\right)$ are the pre-launch calibration constants (607.76 and 1260.56 , respectively, for TM).

According to Wukelic et al. [35] and Washburne [36], the satellite temperatures derived from Landsat thermal band data are good approximations (within $1-3{ }^{\circ} \mathrm{C}$ ) of ground temperature values on clear days. Further calibration requires local soil and vegetation information to estimate emissivity $[37,38]$. Therefore, we did not apply further complex corrections, and adopted Ts directly as the surrogate of LST (Figure 3e).

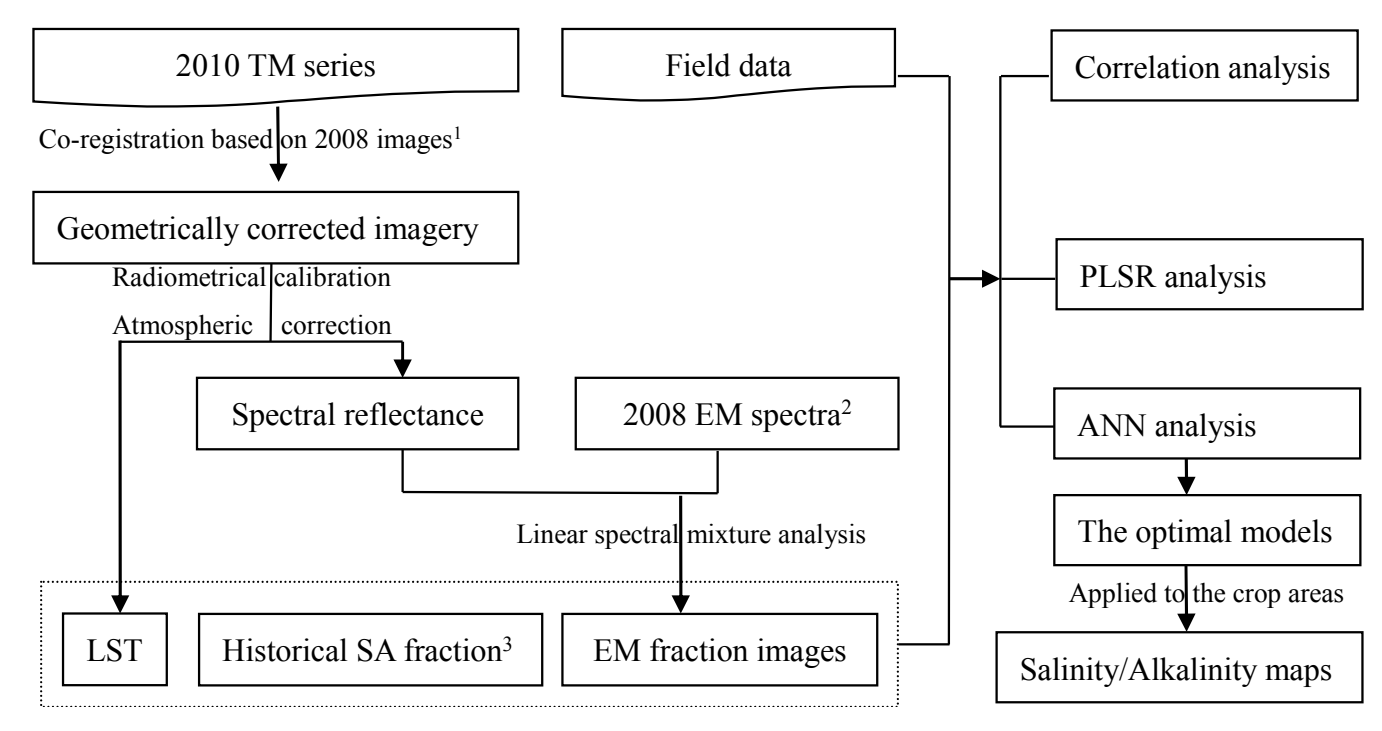

Figure 2. Flowchart of methods used in the study. ${ }^{1}$ The 2008 images are geometrically rectified in Reference [21]; ${ }^{2,3}$ The 2008 EM spectra and historical SA fraction are derived from 2008 images in Reference [21]. ANN: artificial neural network; EM: spectral endmember; LST: land surface temperature; PLSR: partial least squares regression; SA: saline land.

The SA fraction in May 2008 [21]—as the historical SA information representing the potential salt cover with the less/no crops in the dry season-was used to verify the site legacy effect on salt movement due to cultivation in the study area(Figure 3f). In this study, the four nearest-neighboring pixels to the sites were selected, and the EMs' abundance was averaged for use in linking with the field measurements. The LSTs with a $120 \times 120 \mathrm{~m}$ pixel size in the TM5 imagery were extracted from the nearest-neighboring pixel to the site location. 


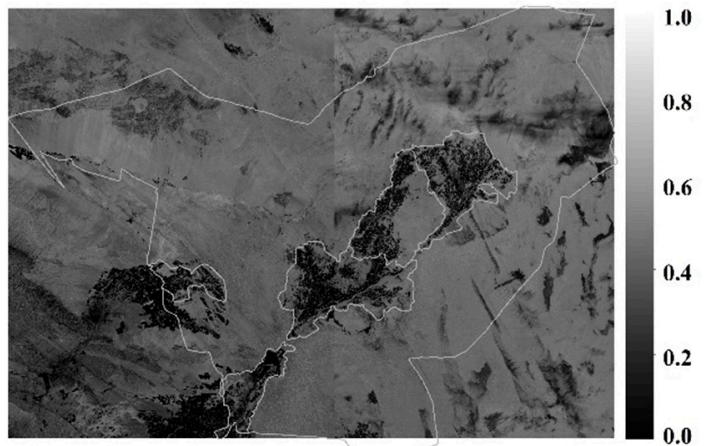

(a) Sand land fraction in August, 2010

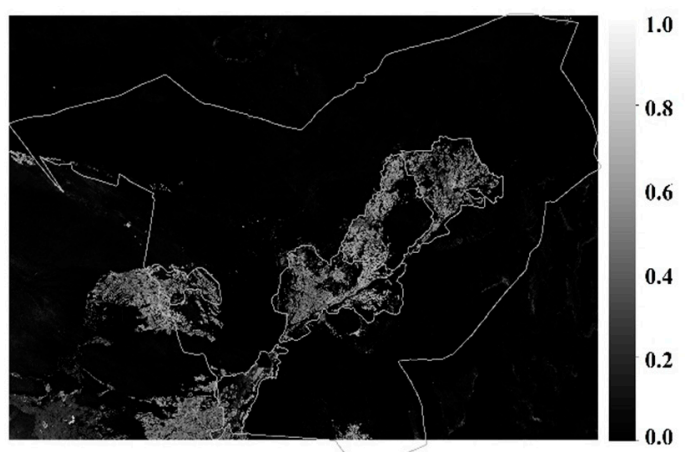

(c) Green vegetation fraction in August, 2010

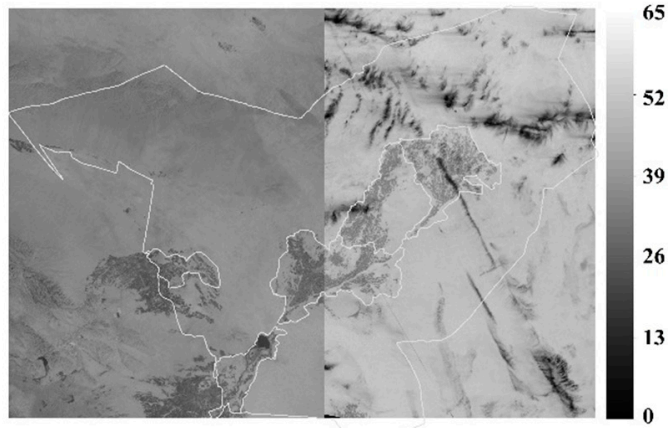

(e) Land surface temperature $\left({ }^{\circ} \mathrm{C}\right)$ in August, 2010

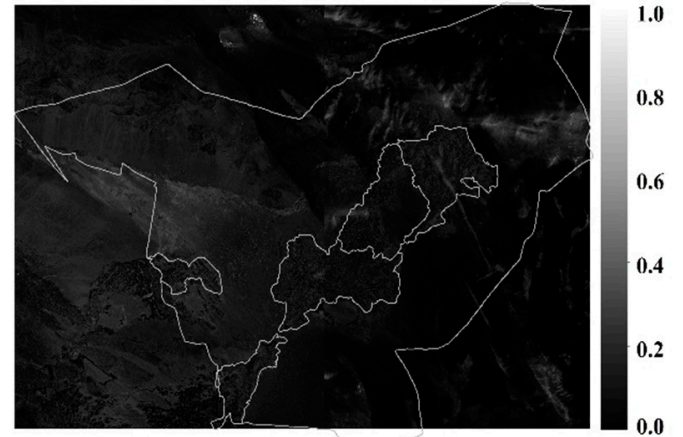

(b) Saline land fraction in August 2010

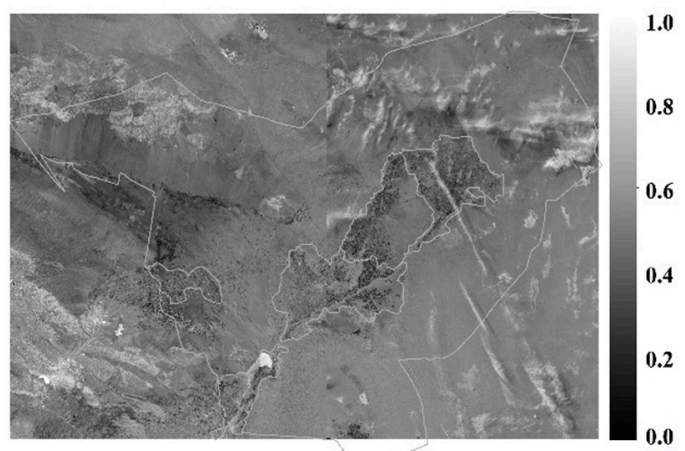

(d) Dark surface fraction in August, 2010

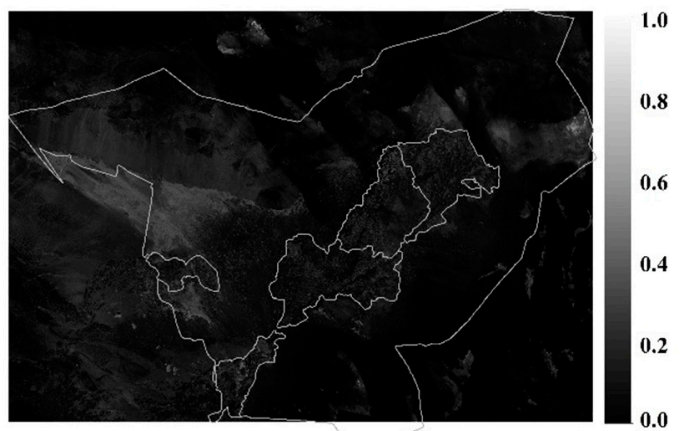

(f) Historical saline land fraction in May, 2008

Figure 3. Spatial distribution of independent variables. (a) SL fraction in 2010; (b) SA fraction in 2010;

(c) GV fraction in 2010; (d) DA fraction in 2010; (e) LST in 2010; (f) SAH in 2008.

\subsection{SVD and LST for Solute Transport Process}

Agricultural alkalization and salinization often appeared homogenous at the field patch level, through long-term irrigation and similar agricultural practices in the dryland oasis [39]. In addition, the iterative leaching down and moving up of the cation and anion components with irrigation activities is the most important mechanism of secondary alkalization in dryland soil [40]. Thereby, agricultural soil alkalinity and salinity in the root zone are dynamic properties associated with the processes of crop growing, solute transport, irrigation, and their interactions in many semi-arid and arid ecosystems.

Aside from salt's osmotic effect on crops with drought-like symptoms [41], soil alkalinity also causes degradation of the soil structure and soil dispersion [42], and thus reduces soil nutrients and water use efficiency for crops. The four-endmember SVD space describes the possible consequences or environmental condition if salts in the root zone impose stress at a sub-30 m resolution. SA is conceptually simple, referring to salt exposure in a pixel, thereby indicating alkalinity and salinity 
status, with little or no vegetation in the dry season condition. A simple correlation analysis was adopted to depict the variables' behaviors.

\subsection{PLSR and ANN Parameters and Calculation}

To quantify PLSR and ANN performance in soil alkalinity and salinity modeling, we calculated diverse parameters between estimated values from models and ground measurements. The root mean squared error (RMSE) indicates absolute estimation errors, whereas the coefficient of determination $\left(\mathrm{R}^{2}\right)$ and ratio of prediction to deviation (RPD) represent the strength of the statistical correlation between measured and predicted values. A predictive model is accurate if $R^{2}$ and RPD values are higher than 0.91 and 2.5, respectively. An $\mathrm{R}^{2}$ between 0.82 and 0.9 and an RPD higher than 2 indicate a good prediction, whereas the $\mathrm{R}^{2}$ of an approximate prediction is considered to lie between 0.66 and 0.81 with an RPD of higher than 1.5. An $\mathrm{R}^{2}$ between 0.5 and 0.65 indicates a poor relationship [26].

In this study, the PLSR modeling was performed using SAS 9.2 software. One-at-a-time cross-validation was used to test the predictive performance of the models with different extracted factors, and the model with the minimum root mean square predicted residual error (RMSEP) was chosen as the calibration model (SAS/STAT(R) 2010). A multiple-layer, feed-forward back-propagation network was used, including input, hidden, and output layers. This type of network generally provides better performance in comparison to other network types [43], and is the most popular neural network structure in ecological modeling and soil science $[44,45]$. Using a tan-sigmoid function in the hidden layer allows us to approximate nonlinear relations between input and output layers [46]. The range of the appropriate number of neurons in a hidden layer is from $\left(2 n^{1 / 2}+m\right)$ to $(2 n+1)$, where $m$ refers to the number of output nodes and $n$ to the number of input nodes [47]. Within the range, the number of neurons in the hidden layer was systematically changed during the process of training the networks, and the most appropriate neurons were selected based on the resulting performance.

The Neural Network Toolbox of MATLAB was used for ANN modeling. The sample dataset was randomly divided into three subsets through several attempts-one subset for training (26 samples), one for validation (six samples), and another for testing (six samples) - the EC statistics of each subset were as close to those of the whole samples as possible (Tables 1 and 2). The Levenberg-Marquardt algorithm was applied to the network training, and only the training data subset was used to adjust the network according to the given error. During the training, the error associated with the validation data subset was monitored. Training was halted when the validation error increased above a specified number of iterations (six times in this study) since the last time it decreased. To avoid the over-fitting problem, the "early stopping" approach was used to halt the training stop process. The testing data subset had no effect on training, and thus its simulation error provided an independent measure of the network performance during and after training.

Table 1. $\mathrm{pH}$ and electrical conductivity (EC) descriptive statistics of the three subsets in the artificial neural networks.

\begin{tabular}{ccccccc}
\hline Soil Variables & Subsets & Sample Number & Mean & Minimum & Maximum & Std. $^{\mathbf{1}}$ \\
\hline \multirow{3}{*}{$\mathrm{pH}$} & training & 26 & 8.57 & 7.70 & 9.89 & 0.44 \\
& validation & 6 & 8.36 & 7.07 & 9.16 & 0.76 \\
& test & 6 & 8.83 & 8.53 & 9.40 & 0.33 \\
\hline \multirow{3}{*}{ EC } & training & 26 & 0.37 & 0.08 & 1.43 & 0.28 \\
& validation & 6 & 0.40 & 0.15 & 1.15 & 0.38 \\
& test & 6 & 0.33 & 0.07 & 0.91 & 0.31 \\
\hline
\end{tabular}

${ }^{1} \mathrm{Std}$. is the representative of standard deviation. 
Table 2. Variables' descriptive statistics in this study (38 sites).

\begin{tabular}{ccccccc}
\hline Variables & Definition & Unit & Mean & Minimum & Maximum & Std. ${ }^{\mathbf{1}}$ \\
\hline pH & Soil reaction & & 8.58 & 7.07 & 9.89 & 0.49 \\
EC & Soil electrical conductivity & $\mathrm{dS} \cdot \mathrm{m}^{-1}$ & 0.37 & 0.07 & 1.43 & 0.29 \\
$\mathrm{SL}$ & Sand land fraction & & 0.19 & 0 & 0.52 & 0.15 \\
$\mathrm{SA}$ & Saline land fraction & & 0.09 & 0.01 & 0.2 & 0.04 \\
$\mathrm{GV}$ & Green vegetation fraction & & 0.29 & 0.01 & 0.81 & 0.23 \\
$\mathrm{DA}$ & Dark surface fraction & & 0.43 & 0.1 & 0.61 & 0.11 \\
$\mathrm{SAH}$ & Historical saline land fraction in 2008 & & 0.11 & 0.01 & 0.23 & 0.06 \\
$\mathrm{LST}$ & Land surface temperature & ${ }^{\circ} \mathrm{C}$ & 36.13 & 25.02 & 51.87 & 7.55 \\
\hline
\end{tabular}

${ }^{1} \mathrm{Std}$. is representative of standard deviation.

\section{Results}

\subsection{The Basic Description of Independent and Dependent Variables in the Study Area}

Table 2 shows that $\mathrm{pH}$ values from all of the 38 sample locations were $>7$. The highest soil $\mathrm{pH}$ was 9.89 , and the mean value was 8.58 , indicating a strong alkalization process. The soil maximum EC was $1.43 \mathrm{dS} \cdot \mathrm{m}^{-1}$ (1:5 soil-water extraction), which converted to its saturated paste extract EC (i.e., $8.58 \mathrm{dS} \cdot \mathrm{m}^{-1}$ ), and belonged to moderate salinization. However, the mean value of $0.37 \mathrm{dS} \cdot \mathrm{m}^{-1}$ was non-saline soil in the shallow root zone.

Figure 3a-d lists the calculated fractions of the four EMs, indicating the amount and spatial distribution of surface characteristics. It is difficult to notice clouds on the GV fraction image (Figure 3c), whereas they are clear in the SL fraction (Figure 3a) and DA fraction (Figure 3d) images. The different dates of the neighbor scenes have some influence on the fraction values (e.g., the SL fraction image, Figure 3a). Figure 3e shows the spatial variability of LST in the study area; LST at the left 132/33 scene (on 23 August 2010) is generally lower than that at the right 131/33 scene (on 15 July 2010). The difference between the neighboring croplands, however, is small. Based on the local meteorological observations $\left(38.63^{\circ} \mathrm{N}, 103.08^{\circ} \mathrm{E} ; 1367.5 \mathrm{~m}\right.$ elevation), the canopy temperature at the local time of the Landsat passing was $28.7^{\circ} \mathrm{C}$ on 15 July and $27.4^{\circ} \mathrm{C}$ on 23 August 2010, respectively. The corresponding estimated LSTs from TM were $31.8^{\circ} \mathrm{C}$ and $30.1^{\circ} \mathrm{C}$, respectively, both approximately $3{ }^{\circ} \mathrm{C}$ higher than the ground direct observation values.

Table 3 shows that the historical SA fraction (SAH) in the 2008 spring season had a 0.1 level significant positive correlation with the soil EC, and a 0.1 level negative correlation with the soil $\mathrm{pH}$, respectively, in the 2010 crop season. In addition, the SAH had a 0.05 level positive correlation with the SA fraction in the 2010 crop season. These results validate SA in the dry season condition with little or no vegetation, and can indicate alkalinity and salinity information, and a certain legacy effect existing on salt movement in dryland agricultural soil. As a result of agricultural practices such as irrigation and/or crop shading, there is often no clear or only partial evidence of salt crust or similar features on the soil surface in the cropping season. As such, the SA fraction in 2010 had no significant correlation with the soil EC or $\mathrm{pH}$.

Clearly, the hidden information can possibly be compensated from other EMs. For example, GV (indicating crop vigor) is the response of the soil quality and agricultural practices. The illuminated SL fraction provides some soil structure condition for solute transport in the soil profile. DA-the sensed surface brightness (determined by dry plant and crop residues, shade, soil dispersion)—also gives some environmental condition information. LST, as an important solute transportation driver, is also a response of the cropland environment. Thus, LST had a significant positive correlation (0.05 level) with the soil EC, and a 0.01 level significant correlation with SL and GV (Table 2). However, these basic cover fractions, due to representing parts of the condition of the cropland individually, were not significantly correlated with soil alkalinity and salinity (i.e., $\mathrm{pH}$ and EC) in the shallow root zone, respectively (Table 3). They should thus be integrated together for solute transport modeling. 
Table 3. Correlation coefficients of each pairwise variable at 38 sites.

\begin{tabular}{ccccccccc}
\hline Variables & pH & EC & SL & SA & GV & DA & SAH & LST \\
\hline pH & 1 & $-0.569^{* * *}$ & 0.217 & -0.002 & -0.137 & -0.013 & $-0.304^{*}$ & 0.127 \\
EC & & 1 & 0.123 & 0.147 & -0.129 & 0.044 & $0.313^{*}$ & $0.36^{* *}$ \\
SL & & & 1 & $0.329^{* *}$ & $-0.879^{* * *}$ & $0.337^{* *}$ & $0.014^{* * *}$ & $0.804^{* * *}$ \\
SA & & & & 1 & $-0.435^{* * *}$ & 0.08 & $0.38^{* *}$ & 0.252 \\
GV & & & & & 1 & $-0.716^{* * *}$ & 0.001 & $-0.607^{* * *}$ \\
DA & & & & & & 1 & -0.165 & 0.068 \\
SAH & & & & & & & 1 & 0.005 \\
LST & & & & & & & & 1 \\
\hline
\end{tabular}

$* * *, * * *$ Correlation is significant at the $0.01,0.05,0.1$ levels, respectively.

\subsection{PLSR Models for Soil Salinity and Alkalinity Estimation}

Figure 4 indicates that a single factor provided the minimum RMSEP for $\mathrm{pH}$ estimation, and four factors for EC prediction. Table 4 provides the performance statistics of the developed PLSR calibration models, the standardized coefficients of predictor variables in each model, and the results of the bootstrap tests. For $\mathrm{pH}$, only $11 \%$ of the variability was explained by the first factor, and the PLSR model of EC performed a little better, with $36 \%$ of the variability being explained by the first four latent variables. As the historical saline land fraction, SAH in the 2008 spring season was a notable variable in the $\mathrm{pH}$ model, with a relatively large and significant standardized coefficient at the 0.1 level (Table 4). In the EC model, only SA failed to pass the bootstrap tests at different significance levels, implying that SL, GV, DA, SAH, and LST all make some linear contribution to soil EC estimation (Table 4). The poor explanatory abilities of the PLSR-calibration models for $\mathrm{pH}$ and EC suggest that the linear model cannot accurately describe the complex relationship among these variables in crop growing.
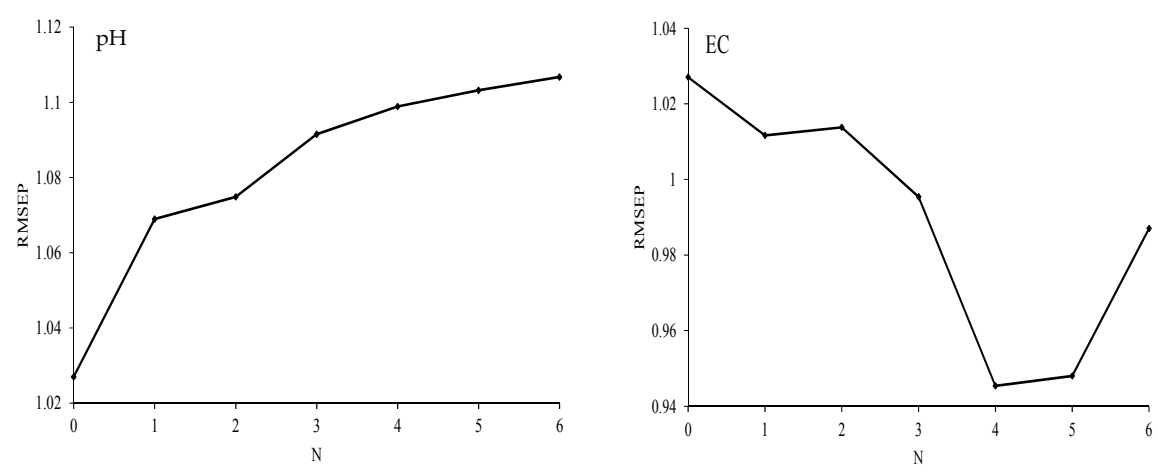

Figure 4. Cross-validation results of PLSR. RMSEP: root mean square predicted residual error.

Table 4. Performance statistics, standardized coefficients, and bootstrap tests of PLSR calibration models. RPD: ratio of prediction to deviation.

\begin{tabular}{|c|c|c|c|c|c|c|c|c|c|c|}
\hline & \multirow{2}{*}{$\mathbf{N}$} & \multicolumn{3}{|c|}{ Performances } & \multicolumn{6}{|c|}{ Standardized Coefficients } \\
\hline & & RPD & $\mathbf{R}^{2}$ & RMSE & SL & SA & GV & DA & SAH & LST \\
\hline $\mathrm{pH}$ & 1 & 0.35 & 0.11 & 0.46 & 0.13 & 0 & -0.08 & -0.01 & $-0.19 *$ & 0.08 \\
\hline EC & 4 & 0.75 & 0.36 & 0.23 & $-0.56^{* *}$ & 0.01 & $0.18^{* *}$ & $0.39 * *$ & $0.4^{* * *}$ & $0.86^{* * *}$ \\
\hline
\end{tabular}

\subsection{Neural Network Models for Salinity and Alkalinity Estimation}

First, all six predictor variables were sent into the input layer. Within the range of nodes recommended, the neuron number in the hidden layer was adjusted to improve the network structure 
for soil salinity and alkalinity estimation. Compared with the PLSR models, ANN models improved $\mathrm{R}^{2}$ from 0.11 to 0.76 and from 0.36 to 0.66 for $\mathrm{pH}$ and $\mathrm{EC}$, respectively. Simultaneously, RMSE values decreased from 0.46 to 0.24 and from 0.23 to 0.17 for $\mathrm{pH}$ and EC, respectively, as shown in Tables 4-6.

We then eliminated one variable from the predictor sets at a single observation time-based on its linear contribution in the PLSR models-to determine the optimized surface parameters and network structure. The elimination of any predictor variable from the $\mathrm{pH}$ ANN model reduced the prediction accuracy (Table 5). The model without LST decreased the most ( $\mathrm{R}^{2}$ from 0.76 to 0.68$)$. The DA also played an important role in the nonlinear model ( $\mathrm{R}^{2}$ from 0.76 to 0.71 , Table 5).

Table 5. ANN model performances of the different predictor variable combinations for soil pH estimation.

\begin{tabular}{|c|c|c|c|c|c|c|c|c|c|c|}
\hline \multirow{2}{*}{$\mathrm{pH}$} & \multirow{2}{*}{ Predictor Variable Combinations } & \multicolumn{9}{|c|}{$\mathbf{N}$} \\
\hline & & 5 & 6 & 7 & 8 & 9 & 10 & 11 & 12 & 13 \\
\hline \multirow{7}{*}{$\mathrm{R}^{2}$} & ALL & 0.70 & 0.76 & 0.66 & 0.64 & 0.67 & 0.66 & 0.68 & 0.72 & 0.65 \\
\hline & ALL-SA & 0.70 & 0.66 & 0.60 & 0.63 & 0.60 & 0.57 & 0.64 & & \\
\hline & ALL-DA & 0.71 & 0.68 & 0.71 & 0.71 & 0.69 & 0.69 & 0.70 & & \\
\hline & ALL-LST & 0.61 & 0.61 & 0.60 & 0.68 & 0.68 & 0.60 & 0.60 & & \\
\hline & ALL-GV & 0.70 & 0.70 & 0.70 & 0.69 & 0.70 & 0.66 & 0.66 & & \\
\hline & ALL-SL & 0.65 & 0.70 & 0.67 & 0.69 & 0.69 & 0.66 & 0.66 & & \\
\hline & ALL-SAH & 0.71 & 0.73 & 0.66 & 0.70 & 0.67 & 0.60 & 0.68 & & \\
\hline \multirow{7}{*}{ RMSE } & ALL & 0.27 & 0.24 & 0.28 & 0.30 & 0.28 & 0.29 & 0.28 & 0.26 & 0.29 \\
\hline & ALL-SA & 0.28 & 0.29 & 0.32 & 0.30 & 0.31 & 0.32 & 0.30 & & \\
\hline & ALL-DA & 0.26 & 0.28 & 0.27 & 0.27 & 0.27 & 0.27 & 0.28 & & \\
\hline & ALL-LST & 0.31 & 0.31 & 0.32 & 0.29 & 0.28 & 0.31 & 0.33 & & \\
\hline & ALL-GV & 0.27 & 0.27 & 0.27 & 0.30 & 0.27 & 0.29 & 0.29 & & \\
\hline & ALL-SL & 0.32 & 0.27 & 0.28 & 0.27 & 0.27 & 0.29 & 0.28 & & \\
\hline & ALL-SAH & 0.26 & 0.26 & 0.29 & 0.30 & 0.30 & 0.33 & 0.28 & & \\
\hline
\end{tabular}

$\mathrm{N}=$ neuron number in the ANN hidden layer, ALL = all the predictor variables (SL, SA, GV, DA, SAH, and LST). "-" means the elimination of one or some predictor variables from ALL. $\mathrm{R}^{2}$ and RMSE of the optimal hidden-layer neuron number for each predictor variables set are bolded.

However, the variable elimination can improve the prediction ability of ANN for soil EC. The model without DA increased to the greatest accuracy ( $\mathrm{R}^{2}$ from 0.66 to 0.74 and RMSE from 0.17 to 0.15 ), and the model excluding SAH came second (Table 6). For the five predictor variables (without DA) to produce the best nonlinear fit for EC, we continued to exclude each one in turn to determine whether there was any associated improvement in prediction accuracy. We found that the removal of any variable except SAH reduced the precision of the model fit (Table 6). Thus, the combination of SL, SA, GV, and LST (with the removal of DA and SAH) improved the most $\left(\mathrm{R}^{2}\right.$ from 0.66 to 0.79$)$. There was no further improvement of the model fit from subsequent exclusion experiments. As shown for the estimation of $\mathrm{pH}$, the elimination of LST from the SL, SA, GV, and LST combination also produced a sharp reduction of the EC prediction accuracy $\left(\mathrm{R}^{2}\right.$ decreased from 0.79 to 0.65 and RMSE increased from 0.13 to 0.17 , Table 6).

The above results give the final optimal ANN for soil $\mathrm{pH}$ prediction in terms of $\mathrm{R}^{2}(0.76)$ and RMSE (0.24) values when the input layer is composed of all the predictor variables and the hidden layer contains six neurons. For soil EC prediction, the network with SL, SA, GV, and LST in the input layer and nine neurons in the hidden layer achieved the highest $\mathrm{R}^{2}(0.79)$ and the smallest RMSE (0.13) values. Figure 5 shows that both the $\mathrm{pH}$ and EC ANN models learn quickly, and their respective MSE (mean squared error) values decrease sharply with respect to the training samples to below 0.01 after only eight epochs. The MSE values of validation samples and test samples became stable only after 15 and 12 epochs for $\mathrm{pH}$ and EC ANNs, respectively. The $\mathrm{R}^{2}$ and RMSE values of the training and test datasets shown in Table 7 indicate that the optimal models of $\mathrm{pH}$ and EC learned quite well and had good generalization abilities. However, the performance parameters associated with the validation dataset were poor, which may be due to the different data distributions of the validation dataset and 
the training dataset (e.g., minimum values and standard deviation, Table 1). For the whole dataset, the $\mathrm{pH}$ and EC ANN models both have the approximate prediction abilities $\left(\mathrm{R}^{2}\right.$ values higher than 0.66 and RPD values higher than 1.5), which is also supported by similar RMSE values (Table 7).

Table 6. ANN model performances of the different predictor variable combinations for soil EC estimation.

\begin{tabular}{|c|c|c|c|c|c|c|c|c|c|c|c|}
\hline \multirow{2}{*}{ EC } & \multirow{2}{*}{ Predictor Variable Combinations } & \multicolumn{10}{|c|}{$\mathbf{N}$} \\
\hline & & 4 & 5 & 6 & 7 & 8 & 9 & 10 & 11 & 12 & 13 \\
\hline \multirow{16}{*}{$R^{2}$} & ALL & & 0.64 & 0.63 & 0.65 & 0.65 & 0.64 & 0.61 & 0.64 & 0.65 & 0.66 \\
\hline & ALL-SA & & 0.62 & 0.67 & 0.66 & 0.61 & 0.66 & 0.61 & 0.66 & & \\
\hline & ALL-GV & & 0.67 & 0.67 & 0.67 & 0.66 & 0.69 & 0.66 & 0.66 & & \\
\hline & ALL-DA & & 0.69 & 0.72 & 0.64 & 0.66 & 0.71 & 0.67 & 0.74 & & \\
\hline & ALL-SAH & & 0.63 & 0.61 & 0.68 & 0.62 & 0.63 & 0.66 & 0.71 & & \\
\hline & ALL-SL & & 0.67 & 0.63 & 0.65 & 0.67 & 0.68 & 0.70 & 0.66 & & \\
\hline & ALL-LST & & 0.34 & 0.60 & 0.55 & 0.31 & 0.48 & 0.44 & 0.67 & & \\
\hline & ALL-DA, SA & & 0.61 & 0.67 & 0.66 & 0.68 & 0.64 & & & & \\
\hline & ALL-DA, GV & & 0.68 & 0.72 & 0.73 & 0.70 & 0.69 & & & & \\
\hline & ALL-DA, SAH & & 0.68 & 0.64 & 0.70 & 0.65 & 0.79 & & & & \\
\hline & ALL-DA, SL & & 0.60 & 0.62 & 0.63 & 0.63 & 0.68 & & & & \\
\hline & ALL-DA, LST & & 0.60 & 0.64 & 0.71 & 0.46 & 0.69 & & & & \\
\hline & ALL-DA, SAH, SA & 0.59 & 0.60 & 0.57 & 0.61 & & & & & & \\
\hline & ALL-DA, SAH, GV & 0.66 & 0.67 & 0.71 & 0.78 & & & & & & \\
\hline & ALL-DA, SAH, SL & 0.60 & 0.67 & 0.71 & 0.68 & & & & & & \\
\hline & ALL-DA, SAH, LST & 0.49 & 0.65 & 0.40 & 0.43 & & & & & & \\
\hline \multirow{16}{*}{ RMSE } & ALL & & 0.18 & 0.18 & 0.17 & 0.19 & 0.18 & 0.18 & 0.18 & 0.17 & 0.17 \\
\hline & ALL-SA & & 0.18 & 0.18 & 0.17 & 0.18 & 0.17 & 0.18 & 0.17 & & \\
\hline & ALL-GV & & 0.17 & 0.17 & 0.17 & 0.17 & 0.16 & 0.17 & 0.17 & & \\
\hline & ALL-DA & & 0.17 & 0.15 & 0.19 & 0.17 & 0.16 & 0.18 & 0.15 & & \\
\hline & ALL-SAH & & 0.18 & 0.18 & 0.17 & 0.21 & 0.18 & 0.19 & 0.16 & & \\
\hline & ALL-SL & & 0.17 & 0.18 & 0.18 & 0.17 & 0.16 & 0.22 & 0.17 & & \\
\hline & ALL-LST & & 0.25 & 0.19 & 0.20 & 0.25 & 0.24 & 0.24 & 0.21 & & \\
\hline & ALL-DA, SA & & 0.18 & 0.17 & 0.17 & 0.17 & 0.18 & & & & \\
\hline & ALL-DA, GV & & 0.17 & 0.15 & 0.16 & 0.16 & 0.17 & & & & \\
\hline & ALL-DA, SAH & & 0.17 & 0.19 & 0.16 & 0.17 & 0.13 & & & & \\
\hline & ALL-DA, SL & & 0.18 & 0.18 & 0.18 & 0.18 & 0.16 & & & & \\
\hline & ALL-DA, LST & & 0.22 & 0.18 & 0.16 & 0.21 & 0.16 & & & & \\
\hline & ALL-DA, SAH, SA & 0.19 & 0.18 & 0.20 & 0.18 & & & & & & \\
\hline & ALL-DA, SAH, GV & 0.17 & 0.17 & 0.18 & 0.15 & & & & & & \\
\hline & ALL-DA, SAH, SL & 0.18 & 0.17 & 0.16 & 0.17 & & & & & & \\
\hline & ALL-DA, SAH, LST & 0.21 & 0.17 & 0.24 & 0.22 & & & & & & \\
\hline
\end{tabular}

$\mathrm{N}=$ neuron number in the ANN hidden layer, $\mathrm{ALL}=$ all the predictor variables (SL, SA, GV, DA, SAH, and LST). "-" means the elimination of one or some predictor variables from ALL. $\mathrm{R}^{2}$ and RMSE of the optimal hidden-layer neuron number for each predictor variables set are bolded.

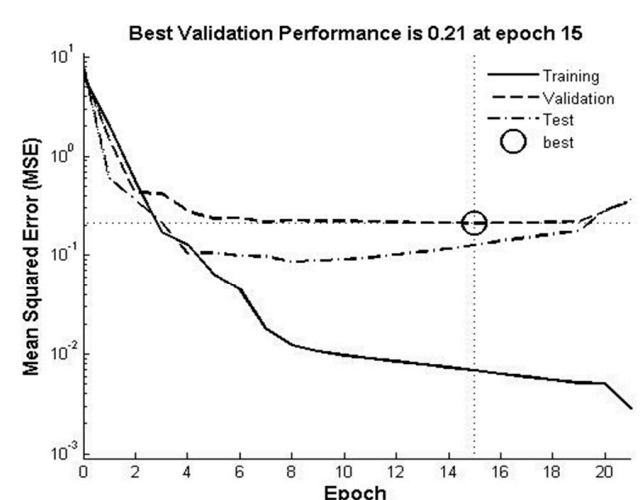

(a)

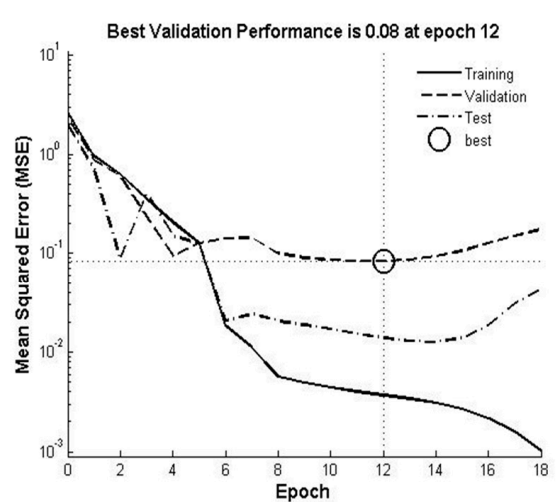

(b)

Figure 5. Mean squared error (MSE) curve of (a) pH and (b) EC optimal ANN model at the phase of learning for training, validation, and test datasets, respectively. 
Table 7. Optimal ANN model performances and parameters for soil $\mathrm{pH}$ and EC estimations.

\begin{tabular}{lccccccccccc}
\hline & \multirow{2}{*}{$\begin{array}{c}\text { Predictor Variable } \\
\text { Combination }\end{array}$} & \multirow{2}{*}{$\mathbf{N}$} & \multicolumn{3}{c}{$\mathbf{R}^{\mathbf{2}}$} & \multicolumn{3}{c}{ RMSE } & \multicolumn{3}{c}{ Predictive Model Parameters } \\
\cline { 3 - 11 } & & & Tra. & Val. & Test & Tra. & Val. & Test & $\mathbf{R}^{\mathbf{2}}$ & RMSE & RPD \\
\hline pH & SL, SA, GV, DA, SAH, LST & 6 & 0.96 & 0.59 & 0.70 & 0.08 & 0.46 & 0.36 & 0.76 & 0.24 & 1.96 \\
$\mathrm{EC}$ & SL, SA, GV, LST & 9 & 0.95 & 0.33 & 0.84 & 0.06 & 0.29 & 0.12 & 0.79 & 0.13 & 1.95 \\
\hline
\end{tabular}

$\mathrm{N}=$ neuron number of hidden layer, Tra. = training, Val. = validation. The unit of RMSE for EC is $\mathrm{dS} \cdot \mathrm{m}^{-1}$.

\subsection{Soil Alkalinity and Salinity Mapping and Classification}

The optimized ANN models for soil $\mathrm{pH}$ and EC predictions were applied to get the contents and classes of soil alkalinity and salinity, respectively, in the 2010 crop season (Figure 6). Commonly, salinity and alkalinity are discriminated following the U.S. Salinity Laboratory (1954) [48], which is highly cited by remote sensing scientists working on soil salinity classification. The predicted EC (1:5 soil-water extraction) was converted to its saturated paste extract EC using a rough multiplying coefficient of 6 [49]. We identified five alkalinity classes according to the simulated $\mathrm{pH}(<7$, non-alkaline; 7-8, slight; 8-8.5, moderate; 8.5-9, strong; $>9$, very strong, Figure $6 \mathrm{c}$ ), and three salinity classes were determined using the saturated paste extract EC ranges in cropland areas (EC: 0-4, non-saline; 4-8, slight; $8-16$, moderate; Figure $6 \mathrm{~d}$ ). Results indicated that $33.44 \%$ and $35.96 \%$ of the agricultural soil was under moderate and strong alkalization, respectively. Furthermore, $15.22 \%$ of the agricultural soil had very strong alkalization in the root zone $(0-20 \mathrm{~cm})$. In contrast, $91.93 \%$ of the agricultural soil was non-saline, and only $7.27 \%$ of the agricultural soil was subject to slight salinization (Table 8 ).

Table 8. The concurrent area of agricultural soil salinity and alkalinity class in the root zone (ha).

\begin{tabular}{|c|c|c|c|c|c|c|}
\hline & Non-Alkaline & Slight Alkaline & $\begin{array}{l}\text { Moderate } \\
\text { Alkaline }\end{array}$ & $\begin{array}{c}\text { Strong } \\
\text { Alkaline }\end{array}$ & $\begin{array}{l}\text { Very Strong } \\
\text { Alkaline }\end{array}$ & $\%$ Total Area \\
\hline Non-saline & 241.65 & $14,519.7$ & $32,378.76$ & $38,041.2$ & $15,937.83$ & 91.93 \\
\hline Slight saline & 10.62 & 1730.43 & 4076.64 & 1432.26 & 738.54 & 7.27 \\
\hline Moderate saline & 2.25 & 406.26 & 328.41 & 77.22 & 68.58 & 0.80 \\
\hline \% Total area & 0.23 & 15.14 & 33.44 & 35.96 & 15.22 & \\
\hline
\end{tabular}

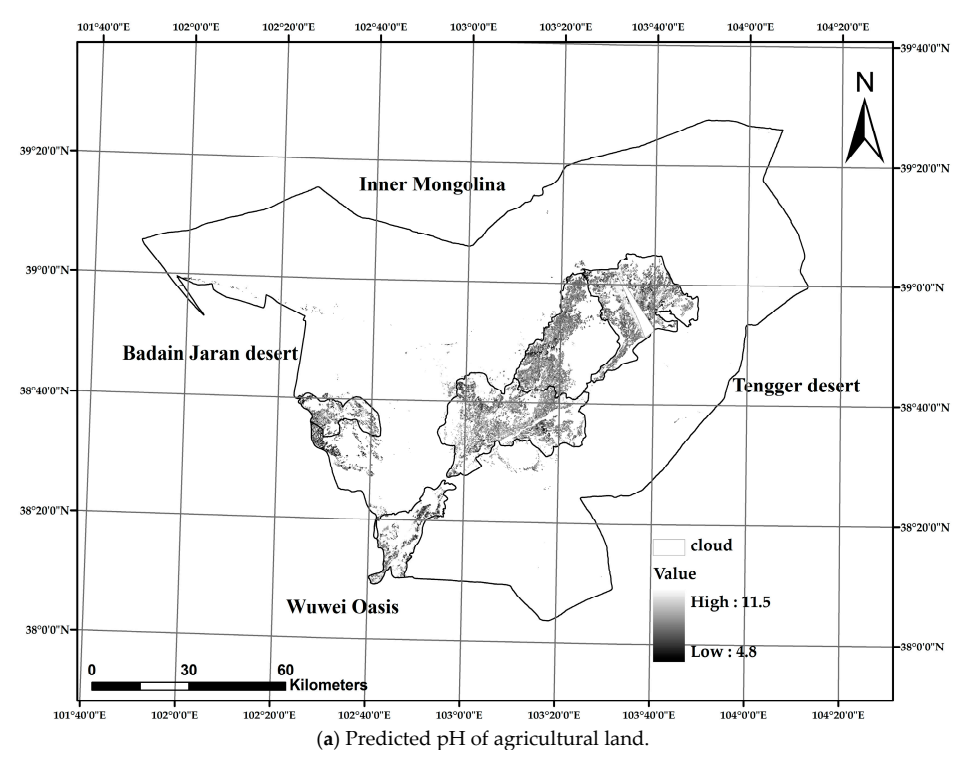

Figure 6. Cont. 


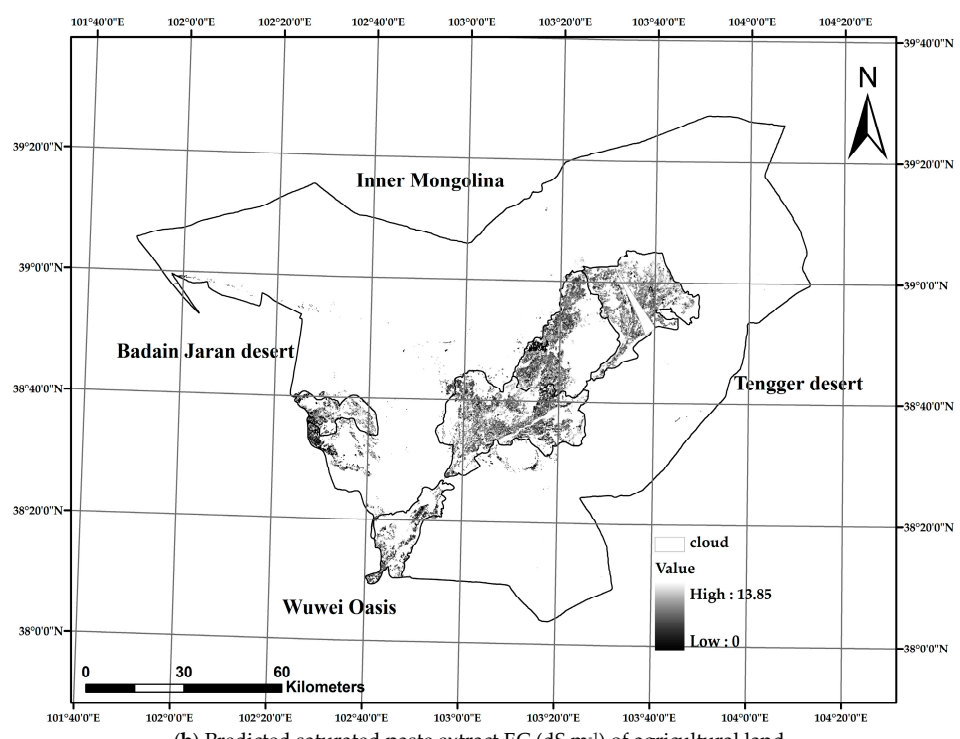

(b) Predicted saturated paste extract EC $\left(\mathrm{dS} \cdot \mathrm{m}^{-1}\right)$ of agricultural land.

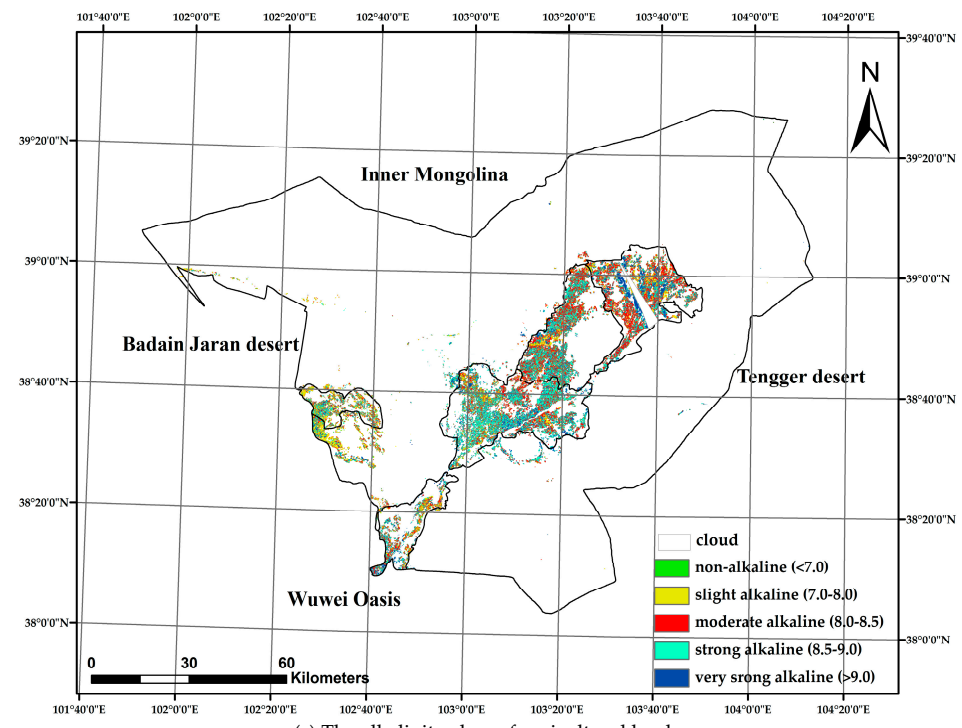

(c) The alkalinity class of agricultural land.

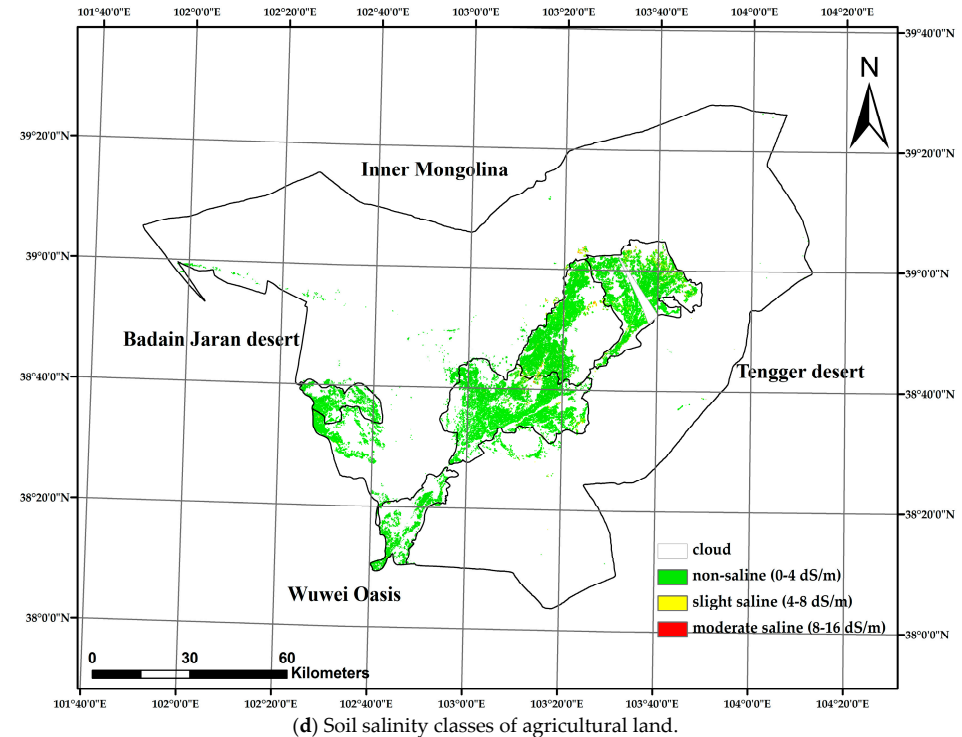

Figure 6. $\mathrm{pH}$ and EC maps (a,b) estimated by the optimal ANN models applied to the agricultural land of study area, and their respective classes $(\mathbf{c}, \mathbf{d})$. 


\section{Discussion}

\subsection{Agricultural Soil Alkalinity and Salinity Modeling in the Study Area}

In this study, the optimized physically-based surface parameters can be identified by the ANN with a series of experiments. The LST, GV, SL, and SA together in both EC and pH models indicate that they can measure the complex cropland environment (in dryland oasis, sandy loam is the major soil) for solute transport processes in the cropping season.

Figure 7a shows the distribution of EC samples in the (LST, GV) feature space; clearly there was a linear trend when GV was below 0.3 in the (LST, GV) space, and thus the samples were divided into two subparts. One group with GV below 0.3 (21 sites) included the samples with the crops harvested, such as winter wheat fields, or those in the final growth phase with sparse green leaves. Figure $7 \mathrm{~b}$ shows the environment under sparse or no green vegetation, where LST and SL determined the transport of salt towards the surface. When SL crosses over a threshold, the soil surface would quickly dry to form a crust sealing the surface, and thus there is reduced vertical transport of salt towards the soil surface. Therefore, standardized coefficients of LST and SL were 1.04 and -0.60 , respectively, and they were linearly combined to depict the solute transportation with $R^{2}=0.53$. However, the other high-GV fraction groups (17 sites) had no explicitly linear relation between EC and the independent variables, partly because EC (low average content in the $0-20 \mathrm{~cm}$ in the study area) was not a major stress for crops (Tables 2 and 8), or the complex mixture between soil evaporation and crop transpiration drove salt accumulation. The mixture is common in most crop-growing periods; therefore, nonlinear models (such as ANN) can better simulate and predict the diverse patterns of EC and pH. LST, as an important energy indicator, can provide surface biophysical process information. However, the coarse spatial resolution influences the wide application of the TM thermal band, compared to the visible-infrared bands. ANN has a certain advantage for fusion of the different resolution parameters, and multi-scale modeling is still a major challenge for the different spatiotemporal resolution data.

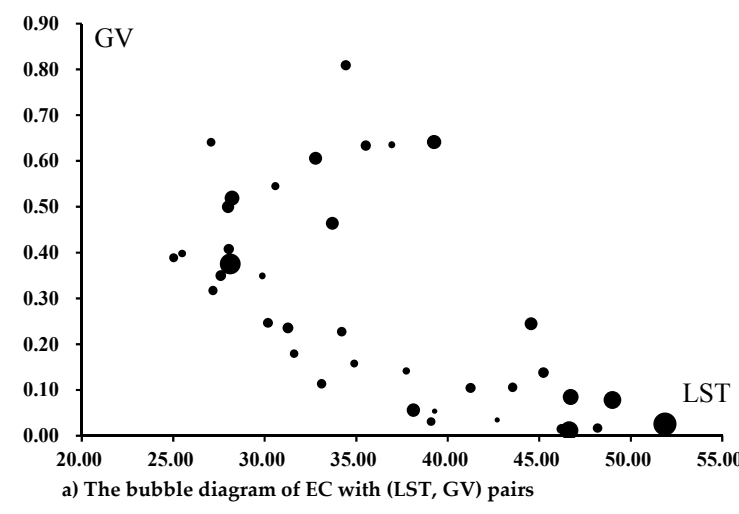

The bubble represents the size of EC

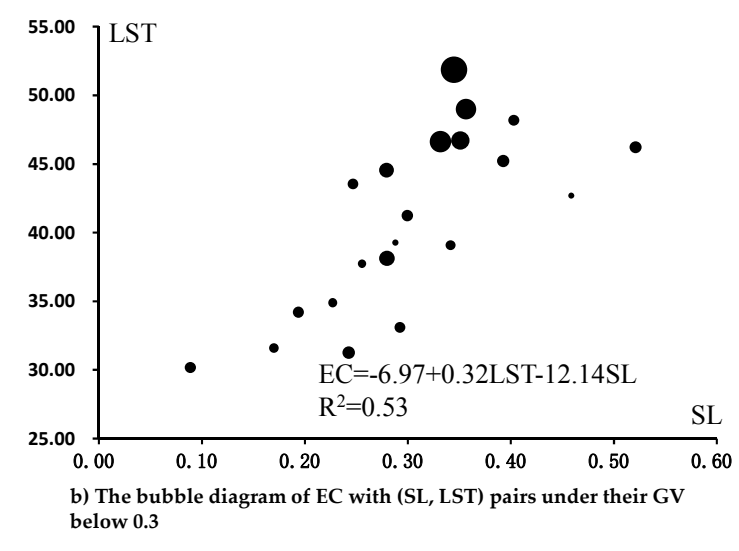

Figure 7. The bubble diagram of EC with the related EMs and LST. (a) The bubble diagram of EC with (LST, GV) pairs; (b) The bubble diagram of EC with (SL, LST) pairs under their GV below 0.3.

Soil $\mathrm{pH}$ is determined by the excessive amount of sodium $\left(\mathrm{Na}^{+}\right)$adsorbed at the cation exchange sites. Thus, with the low salt content in the study area, a strong secondary alkalization process still took place, in which the more soluble $\mathrm{Na}^{+}$ions could easily enrich in the root zone, whereas $\mathrm{Ca}^{2+}$ was stabilized as gypsum and calcium carbonate in the subsoil by the iterative leaching down and moving up with irrigation activities and strong evapotranspiration processes. Thus, the contrast between historical SAH in the dry season and current sensed SA can reflect the redistribution information of cations, and thus SAH entered in the $\mathrm{pH}$ model prediction. Soil EC-indicating the degree of dissolving salts in the soil-always varies seasonally. However, SAH—revealing the site legacy effect on the movement of salts-did not enter the EC ANN model to avoid content redundancy. DA (the mixture of 
dark materials), which may provide some soil dispersion information by alkalization process, was also kept in the $\mathrm{pH}$ ANN model. The use of SAH and DA in the $\mathrm{pH}$ ANN model indicates the difference between the alkalization and salinization processes in the study area.

The stored salts were leached down or out, and surface salinization was ameliorated in the oasis, since the integrated restoration project began in 2005 with about triple the surface water coming into the oasis, instead of groundwater for irrigation [22]. The current study further indicates that an excessive amount of sodium $\left(\mathrm{Na}^{+}\right)$can remain within the shallow root zone. The adequate residue retention, mulching, and no-tillage management can reduce soil evaporation, and thus decrease the vertical transport of sodium towards the surface. The 2009 field sampling ( 90 sites for agricultural land) indicated soil-conservation activities have been adopted; for example, 54.2\% crop residue retention, $84.6 \%$ no-tillage, and $82.1 \%$ plastic mulch in the study area [21]. In addition, deep ploughing and incorporation of calcium supplements (usually gypsum) into the soil are also necessary to leach the excess sodium after several years of continuous cropping. Therefore, the maps of the predicted $\mathrm{pH}$ and EC content and classes (Figure 6) can be used to help farmers adjust crop types and conduct remedial measures to reduce soil alkalinity.

\subsection{Potential of TM SVD for Regional Agricultural Soil Salinity and Alkalinity Mapping in the Root Zone}

The ability of remote sensing data to capture soil-plant relationships changes with salinity and alkalinity, according to geographical context (e.g., References $[4,11])$. Due to the relatively homogenous alkalinity and salinity with the larger field patch in the dryland oasis, the generic and flexible SVD of TM/ETM+ provides an effective scene model of solute transport for near-real-time dryland crop-salts management. In addition, this method is independent of non-remote sensing covariates, which are often associated with mismatch problems in soil alkalinity and salinity modeling at different scales (e.g., Reference [10]).

In this study, ANN, combined with EMs and LST spatial data, can approximately predict agricultural soil salinity and alkalinity in the shallow root zone $(0-20 \mathrm{~cm})$. Figure 5 indicates that the two performance curves of validation and testing deviated from each other, possibly due to some bias between the test and validation samples (Table 1). In this situation, Atzberger and others [50] provide a better learning or training method with a jackknife approach to ensure the stability of the results. This is possible even with a low sampling density of soil $\mathrm{pH}, \mathrm{EC}$, and even with a certain different date range between the ground measurements and satellite imagery recording. However, crop species have various rooting patterns, particularly in high growth periods when the major roots can reach over $30 \mathrm{~cm}$ in depth. In future studies, we will sample additional sites at $0.20 \mathrm{~m}$ depth increments down to $1.5 \mathrm{~m}$, and adopt the recursive jackknife approach developed by Atzberger and others [50] to further optimize the developed approach at different soil depths in different dryland irrigation systems.

Compared to the ANN approach, solute transport modeling is an explicit process-based approach for the prediction of salt distribution and movement in the soil profile in space and time. However, solute modeling is often limited to the points for which field data can be collected [1]; SVD and LST of TM imagery can provide the necessary regional surface parameters for the dynamics of crop growth and solute transport as landscape processes for integrated modeling in a geographical information system environment. In light of this, the proposed integrated approach should be connected to "slow" external drivers resulting from processes at a wider scale (i.e., irrigation infrastructure, terrain and landscape function, land use, and climate change) relating to persistent changes in the dryland agricultural system.

\section{Conclusions}

Soil alkalinity and salinity is one of the most serious hazards for dryland irrigation agriculture. This paper demonstrated for the first time that SVD and LST can effectively describe the solute process in the shallow root zone during crop-growing periods with broadband imagery (e.g., TM/ETM+), and that an ANN can quantify their nonlinear relationship for near-real-time dryland crop management. 
In the study area, the $\mathrm{R}^{2}$ of the $\mathrm{ANN} \mathrm{pH}$ and EC model performance was 0.76 and 0.79 for all sampled data, respectively. In recent years, with about triple the surface water instead of groundwater for irrigation, soil salinization has been ameliorated, and $91.93 \%$ of the agricultural soil was non-saline, whereas alkalization was the major threat, with $33.44 \%, 35.96 \%$, and $15.22 \%$ of the agricultural soil under moderate, strong, and very strong alkalization in the root zone, respectively, in the July-August 2010 cropping period. The developed SVD-LST framework of TM imagery has the potential to monitor dryland alkalinity and salinity with good land management practices for crop production and environmental health.

Acknowledgments: The valuable comments and suggestions from the three anonymous reviewers are much appreciated. We are very grateful to Senior Associate Editor Clement Atzberger for the constructive suggestions, and to the suggestions of remote sensing section of MDPI improving the manuscript. This work was funded by the China Natural Science Foundation (41071146).

Author Contributions: Danfeng Sun proposed the hypothesis, designed the experiments and wrote the paper; Wanbei Jiang performed the experiments, and conducted data processing.

Conflicts of Interest: The authors declare no conflict of interest.

\section{References}

1. Farifteh, J.; Farshad, A.; George, R.J. Assessing salt-affected soils using remote sensing, solute modeling, and geophysics. Geoderma 2006, 130, 191-206. [CrossRef]

2. Kassas, M. Seven paths to desertification. Desertification Control Bull. 1987, 15, $24-26$.

3. King, C.; Thomas, D.S. Monitoring environmental change and degradation in the irrigated oases of the Northern Sahara. J. Arid Environ. 2014, 103, 36-45. [CrossRef]

4. Allbed, A.; Kumar, L.; Sinha, P. Mapping and modeling spatial variation in soil salinity in the Al Hassa Oasis based on remote sensing indicators and regression techniques. Remote Sens. 2014, 6, 1137-1157. [CrossRef]

5. Fan, X.W.; Liu, Y.B.; Tao, J.M.; Weng, Y.L. Soil salinity retrieval from advanced multi-spectral sensor with partial least square regression. Remote Sens. 2015, 7, 488-511. [CrossRef]

6. Zhang, W.T.; Wu, H.Q.; Gu, H.B.; Feng, G.L.; Wang, Z.; Sheng, J.D. Variability of soil salinity at multiple spatio-temporal scales and the related driving factors in the oasis areas of Xinjiang, China. Pedosphere 2014, 24, 753-762. [CrossRef]

7. Tanji, K.K.; Kielen, N.C. Agricultural drainage water management in arid and semi-arid areas. In $F A O$ Irrigation and Drainage; Food and Agriculture Organization of the United Nations: Rome, Italy, 2002; p. 61.

8. Flowers, T.J.; Colmer, T.D. Salinity tolerance in halophytes. New Phytol. 2008, 179, 945-963. [CrossRef] [PubMed]

9. Bai, L.; Wang, C.Z.; Zang, S.Y.; Zhang, Y.H.; Hao, Q.N.; Wu, Y.X. Remote sensing of soil alkalinity and salinity in the Wuyu'er-Shuangyang River Basin, Northeast China. Remote Sens. 2016. [CrossRef]

10. Scudiero, E.; Skaggs, T.H.; Corwin, D.L. Regional-scale soil salinity assessment using Landsat ETM+ canopy reflectance. Remote Sens. Environ. 2015, 169, 335-343. [CrossRef]

11. Sidike, A.; Zhao, S.; Wen, Y. Estimating soil salinity in Pingluo County of China using QuickBird data and soil reflectance spectra. Int. J. Appl. Earth Obs. Geoinf. 2014, 26, 156-175. [CrossRef]

12. Dwivedi, R.S.; Rao, B.R.M. The selection of the best possible Landsat TM band combination for delineating salt-affected soils. Int. J. Remote Sens. 1992, 13, 2051-2058. [CrossRef]

13. Fernandez-Buces, N.; Siebe, C.; Cram, S.; Palacio, J.L. Mapping soil salinity using a combined spectral response index for bare soil and vegetation: A case study in the former Lake Texcoco, Mexico. J. Arid Environ. 2006, 65, 644-667. [CrossRef]

14. Wu, W.; Mhaimeed, A.S.; Al-Shafie, W.M.; Ziadat, F.; Dhehibi, B.; Nangia, V.; de Pauw, E. Mapping soil salinity changes using remote sensing in Central Iraq. Geod. Reg. 2004, 2, 21-31. [CrossRef]

15. Fan, X.; Pedroli, B.; Liu, G.; Liu, Q.; Liu, H.; Shu, L. Soil salinity development in the yellow river delta in relation to groundwater dynamics. Land Degrad. Dev. 2002, 23, 175-189. [CrossRef]

16. Fan, X.; Weng, Y.; Tao, J. Towards decadal soil salinity mapping using Landsat time series data. Int. J. Appl. Earth Obs. Geoinf. 2006, 52, 32-41. [CrossRef] 
17. Akramkhanov, A.; Vlek, P.L.J. The assessment of spatial distribution of soil salinity risk using neural network. Environ. Monit. Assess. 2012, 184, 2475-2485. [CrossRef] [PubMed]

18. Samuel-Rosa, A.; Heuvelink, G.; Vasques, G.; Anjos, L. Do more detailed environmental covariates deliver more accurate soil maps? Geoderma 2015, 243, 214-227. [CrossRef]

19. Small, C. The Landsat ETM+ spectral mixing space. Remote Sens. Environ. 2004, 93, 1-17. [CrossRef]

20. Small, C.; Milesi, C. Multi-scale standardized spectral mixture models. Remote Sens. Environ. 2013, 136, 442-454. [CrossRef]

21. Sun, D.; Liu, N. Coupling spectral unmixing and multiseasonal remote sensing for temperate dryland land-use/land-cover mapping in Minqin County, China. Int. J. Remote Sens. 2015, 36, 3636-3658. [CrossRef]

22. Sun, D. Detection of dryland degradation using Landsat spectral unmixing remote sensing with syndrome concept in Minqin County, China. Int. J. Appl. Earth Obs. Geoinf. 2015, 41, 34-45. [CrossRef]

23. Asner, G.P.; Bateson, C.A.; Privette, J.L.; Elsaleous, N.; Wessman, C.A. Estimating vegetation structural effects on carbon uptake using satellite data fusion and inverse modeling. J. Geophys. Res. 1998, 103, 28839-28853. [CrossRef]

24. Hall, F.G.; Shimabukuro, Y.E.; Huemmerich, K.F. remote sensing of forest biophysical structure using mixture decomposition and geometric reflectance models. Ecol. Appl. 1995, 5, 993-1013. [CrossRef]

25. Sonnentag, O.; Chen, J.M.; Roberts, D.A.; Talbot, J.; Halligan, K.Q.; Govind, A. Mapping tree and shrub leaf area indices in an ombrotrophic peatland through multiple endmember spectral unmixing. Remote Sens. Environ. 2007, 109, 342-360. [CrossRef]

26. Farifteh, J.; van der Meer, F.; Atzberger, C.; Carranza, E. Quantitative analysis of salt-affected soil reflectance spectra: A comparison of two adaptive methods (PLSR and ANN). Remote Sens. Environ. 2007, 110, 59-78. [CrossRef]

27. Lek, S.; Guégan, J.F. Artificial neural networks as a tool in ecological modeling, an introduction. Ecol. Model. 1999, 120, 65-73. [CrossRef]

28. Dixon, B.; Candade, N. Multispectral land use classification using neural networks and support vector machines: One or the other, or both? Int. J. Remote Sens. 2008, 29, 1185-1206. [CrossRef]

29. Gansu Provincial Water Resources Department; Gansu Provincial Development and Reform Commission. Planning of Key Rehabilitation and Comprehensive Management for Shiyang River Basin; Lanzhou, China, 2007. (In Chinese)

30. Sun, D.; Dawson, R.; Li, H.; Li, B. Modeling desertification change in Minqin county, China. Environ. Monit. Assess. 2005, 108, 169-188. [CrossRef] [PubMed]

31. ISSCAS (Institute of Soil Sciences Chinese Academy of Sciences). Physical and Chemical Analysis Methods of Soils; Shanghai Science Technology Press: Shanghai, China, 1978. (In Chinese)

32. Wu, C.; Murray, A.T. Estimating impervious surface distribution by spectral mixture analysis. Remote Sens. Environ. 2003, 84, 493-505. [CrossRef]

33. Landsat Project Science Office. Landsat 7 Science Data Users Handbook. Goddard Space Flight Center. Available online: http:/ /landsat.gsfc.nasa.gov/?p=12723 (accessed on 26 June 2015).

34. Markham, B.L.; Barker, J.L. Landsat MSS and TM postcalibration dynamic ranges, exoatmospheric reflectances and at-satellite temperatures. EOSAT Landsat Tech. Notes 1986, 1, 3-8.

35. Wukelic, G.E.; Gibbons, D.E.; Martucci, L.M.; Foote, H.P. Radiometric calibration of Landsat Thematic Mapper thermal band. Remote Sens. Environ. 1989, 28, 339-347. [CrossRef]

36. Washburne, J.C. A Distributed Surface Temperature and Energy Balance Model of a Semi-Arid Watershed. Ph.D. Thesis, University of Arizona, Tucson, AZ, USA, 1994.

37. Jiménez Muñoz, J.C.; Sobrino, J.A. A generalized single-channel method for retrieving land surface temperature from remote sensing data. J. Geophys. Res. 2003. [CrossRef]

38. Sobrino, J.A.; Jiménez-Muñoz, J.C.; Paolini, L. Land surface temperature retrieval from LANDSAT TM 5. Remote Sens. Environ. 2004, 90, 434-440. [CrossRef]

39. Yu, Y.; Gu, H.B.; Zhang, L.; Yan, A.; Sheng, J.D.; Chai, Q.; Xie, F.H.; Cai, Y.F. Analysis of soil salt characteristics in oasis farmland. J China Agric. Univ. 2016, 21, 89-95. (In Chinese)

40. Yu, Y.P. Soil alkalinity and its prevention. Soils 1984, 5, 163-170. (In Chinese)

41. Bernstein, L. Effects of salinity and sodicity on plant growth. Annu. Rev. Phytopathol. 1975, 13, $295-312$. [CrossRef] 
42. Huang, P.M.; Li, Y.; Sumner, M.E. Soil Sciences: Resource Management and Environmental Impacts; CRC Press: Boca Raton, FL, USA, 2012.

43. Hornik, K.; Stinchcombe, M.; White, H. Multilayer feedforward networks are universal approximators. Neural Netw. 1989, 2, 359-366. [CrossRef]

44. Dawson, C.W.; Wilby, R.L. Hydrological modeling using artificial neural networks. Prog. Phys. Geogr. 2001, 25, 80-108. [CrossRef]

45. Schultz, A.; Wieland, R.; Lutze, G. Neural networks in agroecological modeling-Stylish application or helpful tool? Comput. Electron. Agric. 2000, 29, 73-97. [CrossRef]

46. Haykin, S. Neural Networks: A Comprehensive Foundation, 2nd ed.; Prentice-Hall Inc.: Upper Saddle River, NJ, USA, 1999.

47. Fletcher, D.; Goss, E. Forecasting with neural networks: An application using bankruptcy data. Inf. Manag. 1993, 24, 159-167. [CrossRef]

48. Richards, L.A. Diagnosis and Improvement of Saline and Alkali Soils; U.S. Department of Agriculture: Washington, DC, USA, 1954.

49. Xin, J.F.; Zhang, G.Y.; Li, Y.Z. The different soil electrical conductivity types and their relations. In Movement of Water-Salts in Salinized Soils; Shi, Y.C., Ed.; Beijing Agricultural University Publishing: Beijing, China, 1985; pp. 151-158.

50. Atzberger, C.; Darvishzadeh, R.; Immitzer, M.; Schlerf, M.; Skidmore, A.; Maire, G. Comparative analysis of different retrieval methods for mapping grassland leaf area index using airborne imaging spectroscopy. Int. J. Appl. Earth Obs. Geoinf. 2015, 43, 19-31. [CrossRef]

(C) 2016 by the authors; licensee MDPI, Basel, Switzerland. This article is an open access article distributed under the terms and conditions of the Creative Commons Attribution (CC-BY) license (http:/ / creativecommons.org/licenses/by/4.0/). 